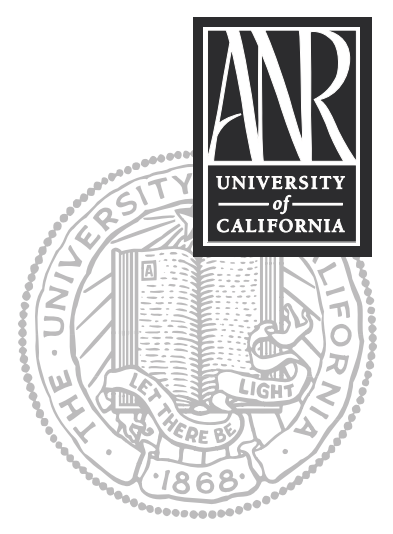

UNIVERSITY OF CALIFORNIA

Division of Agriculture and Natural Resources http://anrcatalog.ucdavis.edu

\title{
Egg Candling and Breakout Analysis
}

R. A. ERNST, F. A. BRADLEY, U. K. ABBOtT and R. M. CRAIG, Animal Science Department, University of California, Davis. Photographs by R. M. CRAIG.

Candling hatching eggs during incubation and breakout examination of the clear eggs or dead embryos are useful tools for hatchery managers to use in maintaining quality assurance and analyzing poor hatches. Other tools include monitoring the temperature of the egg storage room, incubator temperature, incubator humidity, shell quality, chick quality, hatching percentage, bacterial counts in air or on hatchery surfaces, and egg moisture loss during incubation.

This publication illustrates various conditions that may be seen in eggs during candling and describes how to identify infertile eggs and early dead embryos during breakout. It is best used in conjunction with Common Incubation Problems: Causes and Remedies (ANR Publication 8127) and the video Hatching Egg Breakout (ANR Video V86-W) (see "For More Information" at the end of this publication). This publication also contains a glossary of technical terms.

\section{DIAGNOSING POOR HATCHES AND HATCHERY QUALITY ASSURANCE}

If a hatch is poor, identify the cause of the trouble as quickly as possible. A poor hatch may be caused by a failure in fertilization or by excessive mortality of the embryos due to a variety of factors. (For a more complete list of problems, causes, and possible solutions, see Common Incubation Problems).

Careful examination of a sample of eggs to diagnose hatching problems must include not only candling but breakout analysis. Even during problem-free periods, chicken, pheasant, partridge, and quail eggs should be candled after 5 to 7 days of incubation. Turkey, duck, and goose eggs-because of their longer incubation periods-should be candled after 8 to 10 days of incubation. The sample should be candled again at transfer to the hatcher, and dead germs should be broken out and examined. For information on setting up an organized program for commercial hatchery quality control, see Quality Control Procedures for the Hatchery (Mauldin 1993).

\section{SAMPLING}

If small groups of eggs are set, the most appropriate sample is the entire group. If sets exceed 300 eggs, a sample of 100 to 200 eggs should be examined. In large hatcheries, sampling procedures should be carefully planned with the assistance of a statistician or poultry specialist to optimize the quality of the results and minimize costs. During problem periods, more frequent candling and analysis may be advisable. To determine true fertility, breakout analysis is required.

\section{USING THIS PUBLICATION}

The color photos included in this publication help you to distinguish normal, healthy embryos from infertile eggs and "early-deads." Refer to Common Incubation Problems for causes and possible remedies.

The loss of incubated eggs from modern, high-hatching chicken strains, stored under optimal conditions, should be no more than 10 percent at the first candling. 
Losses in turkey, waterfowl, and game bird eggs may be slightly higher. The mortality measured by candling and breakout during the first candling normally represents one-third of the total mortality to be expected. The mortality after the second candling should represent two-thirds of the total to be expected, with very little mortality during midincubation. Mortality during midincubation may indicate a dietary deficiency if infected embryos or developmental abnormalities are not seen. However, the most common nutrient deficiencies result from marginal vitamin levels in the diet and usually cause weak chicks that have difficulty hatching, without other symptoms.

When eggs are candled after the first mortality peak at 7 to 10 days, three distinct classes can be recognized: living normal embryos, blood rings, and clears. If eggs are candled at transfer, clears should not found unless they were missed on the first candling. Dead embryos should be found in small numbers. Some of these may be associated with poor or damaged shells that were not removed during the first candling or that developed after the first candling. Breakout may reveal infected eggs, which can be detected by their abnormal color and odor.

Examination of eggs that fail to hatch reveals several types of abnormalities. Look for malpositioned embryos (other than head under right wing and in the large end of the egg). Excessively wet or dry embryos indicate incorrect incubator humidity, extended or improper (dry) egg storage, or poor shell quality. A few genetically abnormal embryos may be found at this stage, but if numbers are excessive, conduct a more detailed investigation.

\section{LIVING NORMAL EMBRYOS}

Candled living normal embryos show

- clearly defined blood vessels with no hemorrhagic areas evident

- some body movement when stimulated by the candling light

- a generally healthy appearance

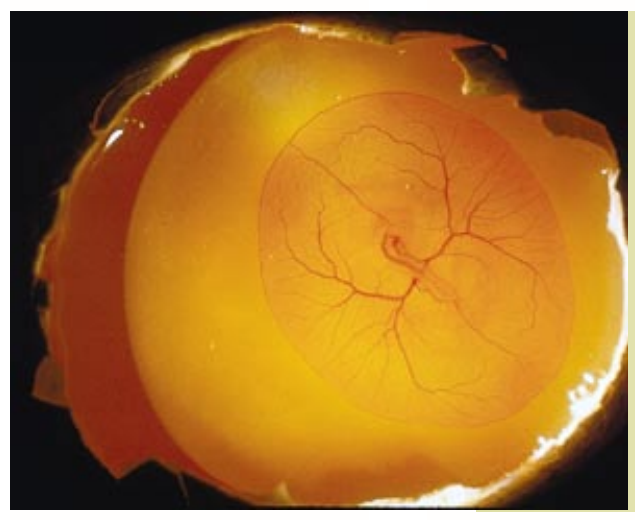

\section{4-day-old normal turkey embryo.}

Use this photo as a reference in determining the developmental age of normal turkey embryos. Note the small, centrally located embryo and the developing blood vessels in the yolk sac membrane.

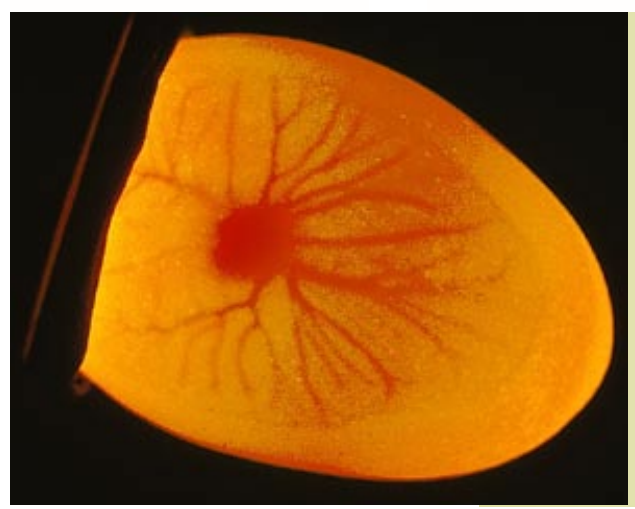

\section{4-day-old normal chicken embryo.}

Note the more advanced circulatory system than in the turkey embryo of equal age. The dark area near the center of the egg is the embryo; the radiating lines are the blood vessels of the extraembryonic membranes (yolk sac). 


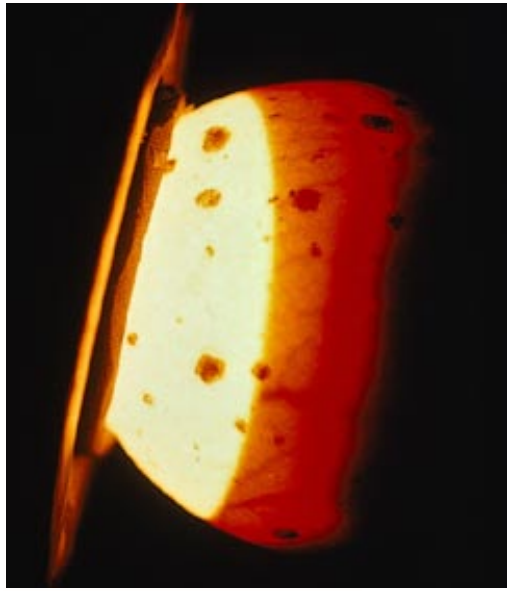

\section{4-day-old normal turkey egg.}

The light upper part (left side of photo) is the enlarged air cell that is required for proper hatching. The dark, lower part contains the embryo. One of the keys to good poult hatchability is the proper amount of "dry down" at the end of the incubation period.

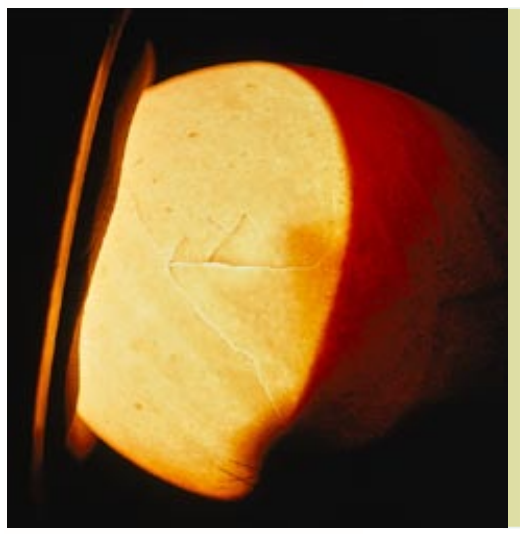

\section{7-day-old normal turkey egg.}

The blood vessels at the lower left of this pipped egg have not yet completely dried up and are still needed for respiration. Humid conditions must be maintained at this stage to prevent premature drying of these vessels and death of the poult.

\section{BLOOD RINGS AND DEAD EMBRYOS}

These eggs show a ring of blood outlined on the inner surface of the shell when candled. They usually contain fairly advanced embryos that have died only recently, but they may also contain a blastoderm without an embryo or a cystic embryo.

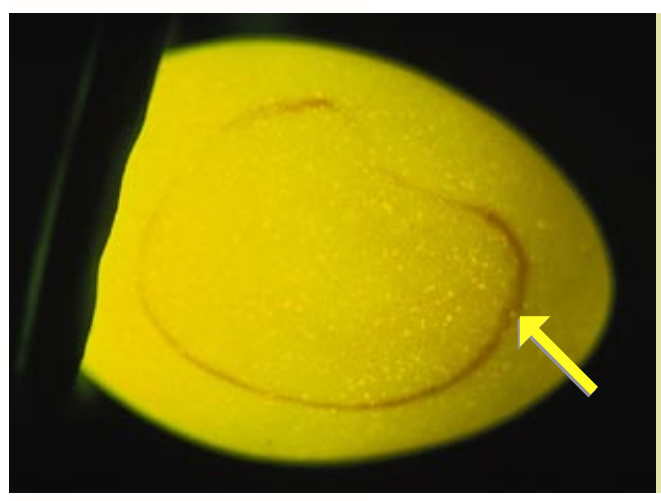

\section{Blastoderm without embryo (BWE) chicken egg.}

The blood ring (arrow) indicates a dead and probably abnormal embryo from a fertile egg. The lack of any visible embryo structure indicates that it is a BWE.

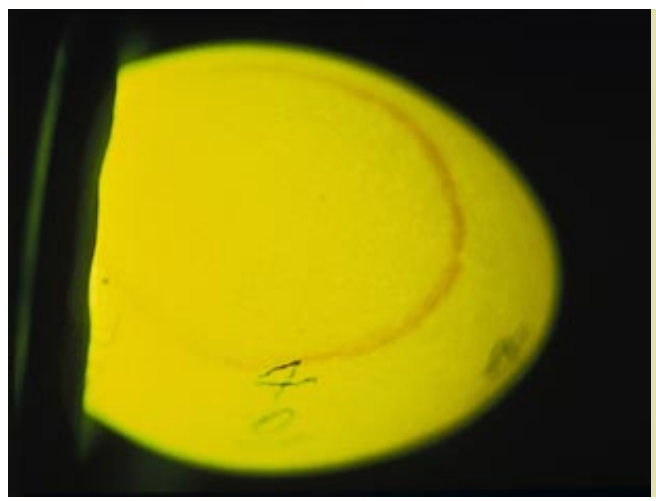

\section{Cystic embryo in chicken egg.}

The candled appearance of an egg with a cystic embryo is similar in appearance to a BWE showing a blood ring. Examined on breakout, a cystic embryo often has heart tissue as the most recognizable normal structure. 


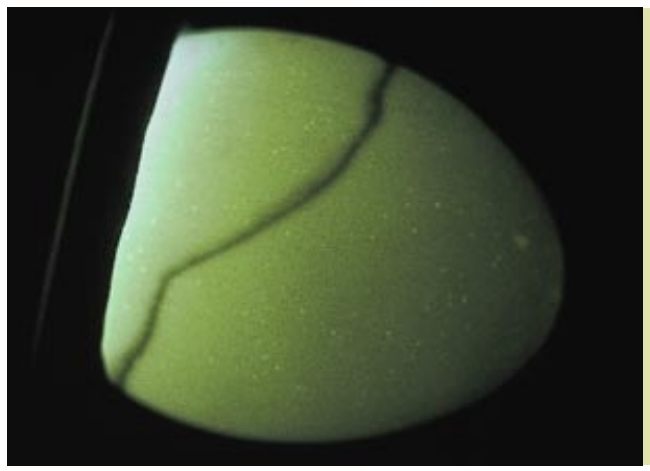

\section{Blood ring in chicken egg.}

The presence of the blood ring in this egg is symptomatic of the early death of an embryo. Diagnosis may be made by breakout analysis.

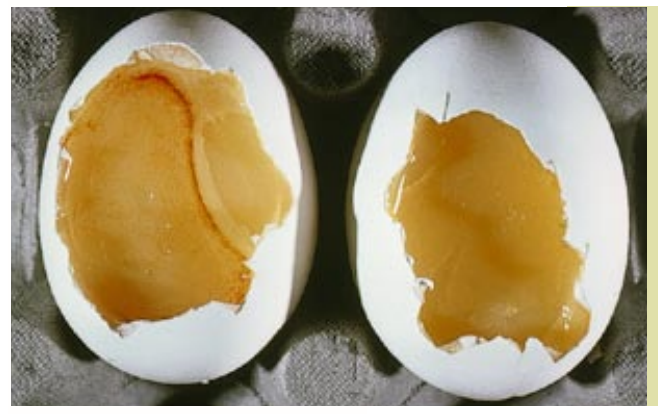

\section{Infertile and blastoderm without embryo (BWE) chicken eggs.}

In these chicken eggs that have been candled out, the infertile egg (right) shows no development. The 21/2-day-old BWE egg (left) shows the typical extraembryonic membranes surrounded by a blood ring.

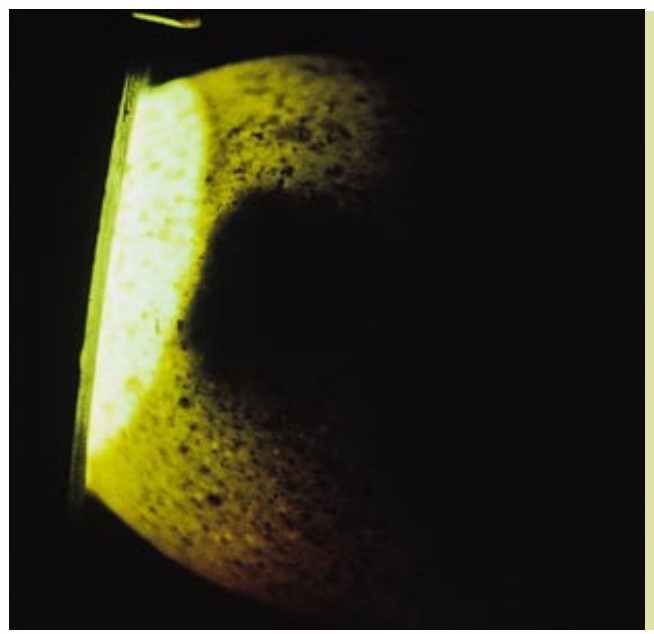

\section{Dead turkey embryo.}

In this turkey egg, candled after 10 days of incubation, the large, dark, round spot and lack of visible blood vessels are the major indications that the embryo is dead.

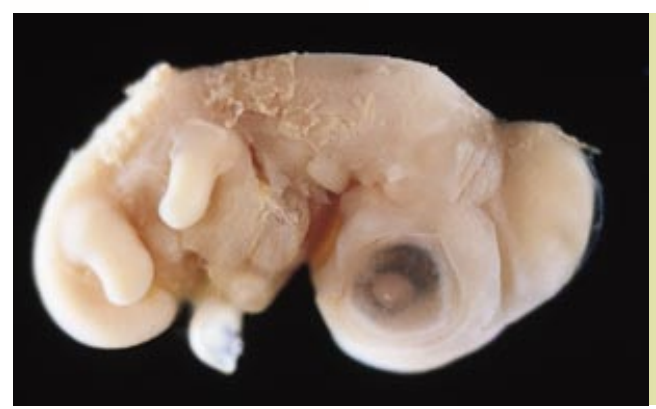

\section{Abnormal turkey embryo.}

This abnormal embryo, about 8 days old, is from an egg candled after 10 days of incubation. The abnormally shaped head and mouthparts indicate developmental disturbances that led to death. Decomposition of tissues, as seen here, is typical of dead embryos.

\section{CLEARS}

The term "clears" refers to eggs that show no development when candled, including

- fertile eggs

- true infertiles

- fertile, no development (FND)

- positive development

Under normal circumstances, more than half of all clears are true infertiles. The other half comprise the dead-embryo categories shown in the photos below; these are not true fertility problems. Especially where they are abundant, the cause of fertility problems must be identified so that proper remedial measures can be taken. 


\section{FERTILE EGGS}

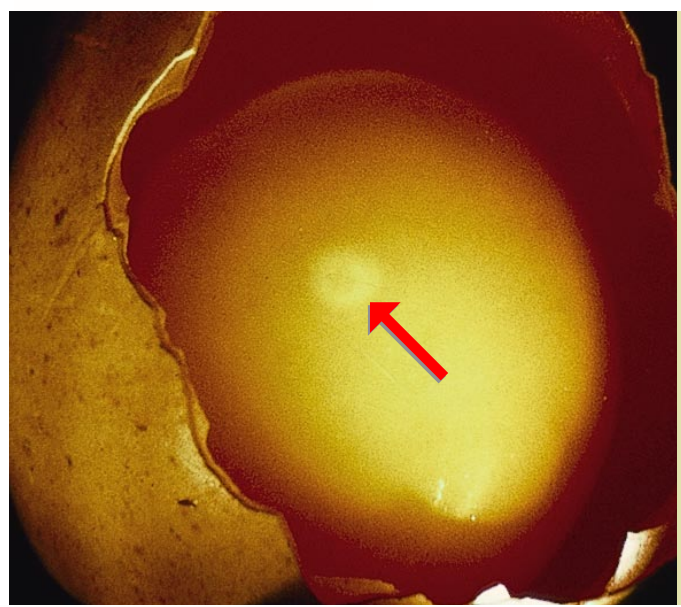

\section{Fertile unincubated turkey egg.}

Characteristic of this fertile egg is the regular, smooth blastodisc (arrow), showing a distinct circular edge.

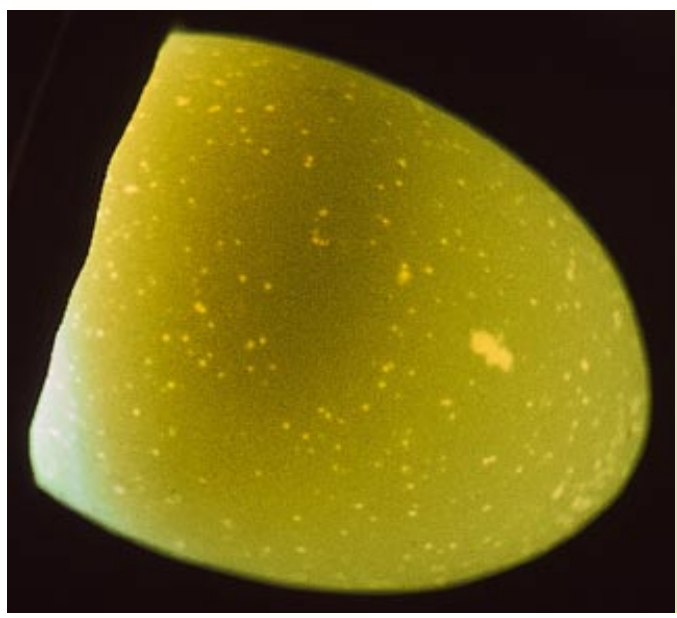

\section{Unincubated chicken egg.}

Candling an unincubated egg does not show whether it will develop properly. The indistinct shadow of the yolk (center) is characteristic of an unincubated egg.

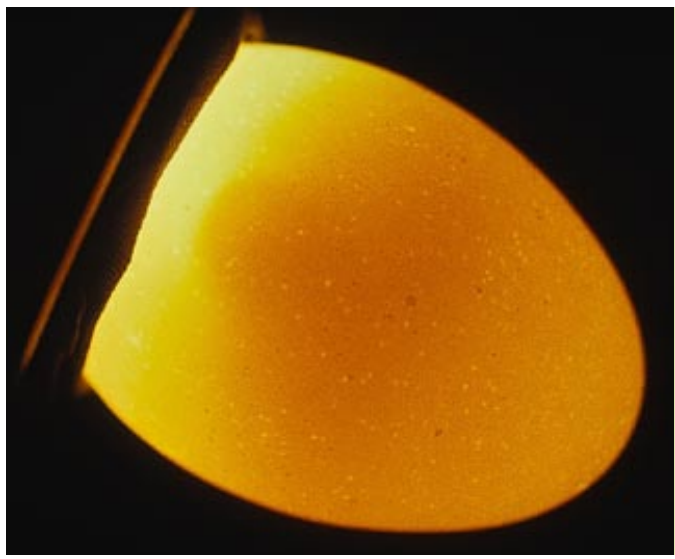

\section{Chicken egg incubated 24 hours.}

Note that the yolk shadow is more distinct than in the unincubated egg, and that it appears near the top, a raised round area where the embryo will develop.

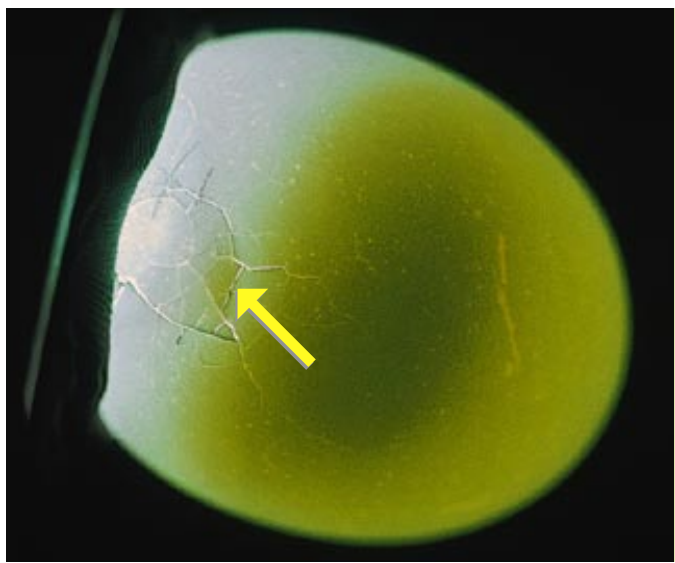

\section{Cracked chicken egg.}

Eggs with cracks, which are not always visible without candling, should be excluded because they are likely to break further and may be contaminated with bacteria or molds that will infect other eggs. 


\section{TRUE INFERTILES}

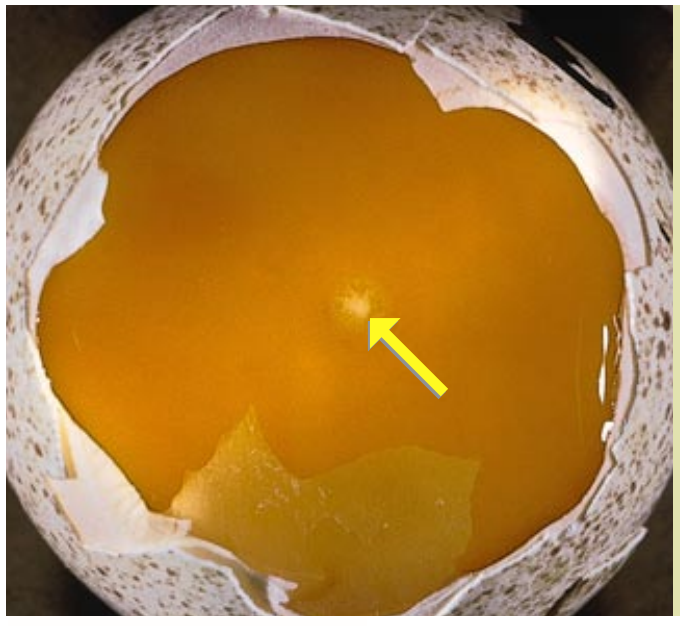

\section{Infertile incubated turkey egg.}

The blastodisc (arrow) is a small light spot surrounded by a disorganized, irregularly shaped fuzzy area.

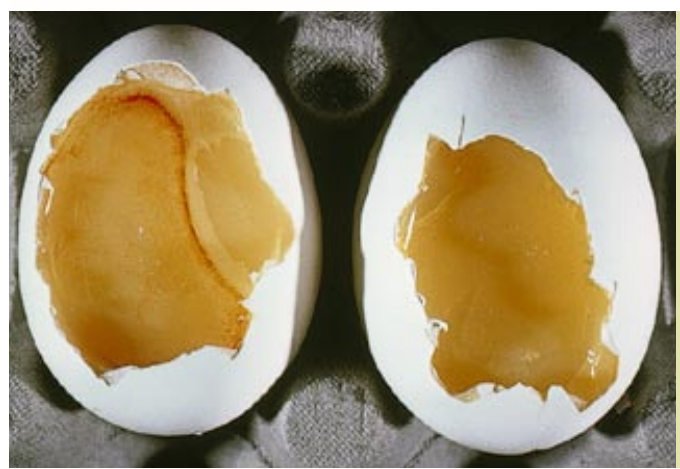

\section{Infertile and blastoderm without embryo (BWE) chicken eggs.}

In these eggs that have been candled out, the infertile egg (right) shows no development, while the 21/2-day-old BWE egg (left) shows the typical extraembryonic membranes surrounded by a blood ring.

\section{FERTILE, NO DEVELOPMENT (FND)}

Fertile eggs without development are infrequently seen. Possible causes include increased frequency of recessive lethal genes in inbred stocks and improper egg storage (see Common Incubation Problems).

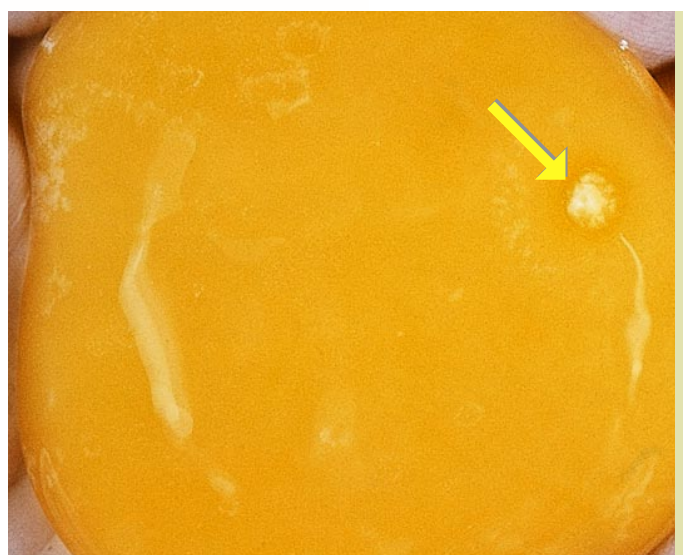

Fertile, preoviposital death, turkey egg.

A rarely seen FND. The egg was incubated for 3 days before being broken out. The blastodisc (arrow) deteriorated but still has the characteristic shape and size of a typical fertile blastodisc.

\section{POSITIVE DEVELOPMENT (PD)}

This is the most frequently seen condition in fertile clears. The embryo dies early, but the growth of cells over the surface of the yolk may continue for several days. Under normal conditions only 1 to 2 percent of the clears are PDs. The incidence increases when eggs are improperly stored or from abuse during shipping. 


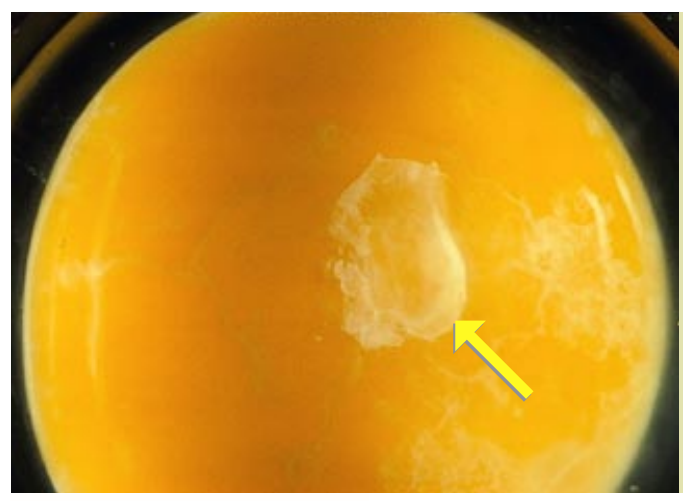

\section{Positive development (PD) in turkey egg.}

This egg contained a fertile germ (arrow) that began to develop and then stopped. Candled, it appears to be clear. Note the absence of blood, as compared to the BWE illustrated above.

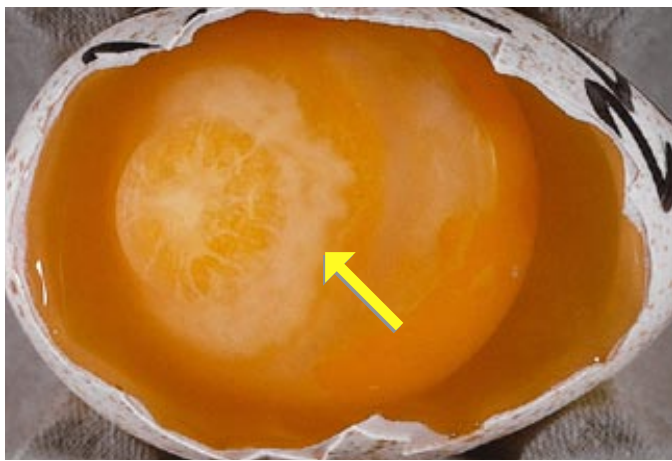

\section{Positive development (PD) in turkey egg.}

This blastoderm has developed further than the one in the previous photo. The absence of blood formation characterizes it as a PD.

\section{GLOSSARY}

blastoderm without embryo (BWE). When candled, a BWE egg shows a blood ring; on breakout there are no visible embryo structures.

blastodisc. The small disc-shaped region on the yolk that contains the egg nucleus.

blood ring. Circular blood remnant visible when an egg is candled; signifies that the embryo has died at a young age.

breakout. Breaking an egg and examining its contents to determine whether the blastodisc was fertilized or embryonic structures were present.

candled fertility. The percentage of eggs remaining after clears are removed by candling; compare with true fertility.

candled out. Clear eggs removed from the incubator following candling.

candling. Transluminating an egg with light to determine the presence or absence of a viable embryo or to look for shell defects before setting.

clears. Incubated eggs that appear clear when candled, indicating that they do not contain a live embryo.

cystic embryo. Embryo that dies early in gestation; the broken-out appearance is similar to a BWE except that embryo tissue is visible.

dry-down. The amount of moisture lost from eggs during incubation.

dry-bulb temperature. Temperature measured with a standard thermometer or electronic sensor; compare with wet-bulb temperature.

embryo. An organism in the early stages of its development before hatching.

fertile, no development (FND). Rarely diagnosed condition in which the blastodisc was fertilized but died before the egg was laid or before growth could be initiated in the incubator.

fertile, preovipositional death. Rarely diagnosed condition characterized by a blastodisc that appears to be fertile but dies before the egg is laid by the hen.

germ, germinal disc. Fertilized blastodisc; the embryo has about 50,000 cells when the egg is laid.

hatch, percent hatch, hatching percent, hatch of total. Percentage of all eggs set that hatch whether they were fertile or not (a typical hatch might be $80 \%$ to $90 \%$ ). 
hatch of fertile eggs, hatchability. Percentage of fertile eggs that hatch (should be above $85 \%$ ).

hatcher. Machine used to maintain proper conditions for embryos during the final few (usually 3) days before hatching.

inbred. Birds or flocks that have some degree of inbreeding.

inbreeding. The result of mating closely related birds, such as father to daughter or brother to sister. As inbreeding increases, the ability of the stock to reproduce usually declines.

incubation. Maintaining the temperature and humidity needed to initiate embryo growth and hatching of avian eggs by a female or using a machine.

incubator, or setter. Machine that maintains proper conditions for incubating or setting avian eggs.

malposition. Hatching embryo in any position except the head under the right wing positioned in the large end of the shell; for example, the head under the left wing or the head between the legs.

parthenogenesis. Development of an egg without fertilization, which occurs at low levels in chickens and turkeys. Parthenogenic embryos usually die; if the embryo hatches it will be a male with a diploid (2n) number of chromosomes. pip. Egg in which the chick has broken the shell in an attempt to hatch; also, the act of breaking the shell. Chicks may die after pipping or may be unable to get out of the shell.

positive development (PD). Eggs that are candled out as clears because there is no blood formation; the germ was fertile, but it died soon after cell growth resumed when the egg was warmed above $80^{\circ} \mathrm{F}\left(26.7^{\circ} \mathrm{C}\right)$.

poult. Young turkey.

relative humidity. Measure of the water vapor or moisture in air; can be determined from the wet-bulb and dry-bulb temperature using a psychometric chart.

set. To place eggs in an incubator or under a female for incubation.

setter. An incubator.

spread. The difference between percent of fertile eggs and percent hatch (a 10\% to $12 \%$ spread is typical for chicken eggs).

true fertility. Percentage of hatching eggs that are fertile. This can be determined only by incubation, candling, and breakout of the clears to determine which eggs were fertile or by breaking out potentially fertile eggs to examine the germinal disc (e.g., a sample might be examined to estimate fertility of a flock).

true infertility. Lack of true fertility.

wet-bulb temperature. Temperature measured by a standard thermometer equipped with a wet sock over the bulb. For accurate measurements, air must be moving over the wet sock to provide evaporation. Electronic sensors are now available to measure the relative humidity of air in incubators and egg storage rooms.

\section{REFERENCE}

Mauldin, J. M. 1993. Quality control procedures for the hatchery. Athens: University of Georgia College of Agricultural Sciences Cooperative Extension Service. 


\section{FOR MORE INFORMATION}

You'll find more information on hatching egg care and incubation in the following ANR products:

Hatching Egg Breakout, Video V86-W, 1986.

Hatching Egg Sanitation: The Key Step in Successful Storage and Production.

Publication 8120, 2004. Available for free downloading from the ANR

Communication Services Web site, http://anrcatalog.ucdavis.edu/pdf/8120.pdf.

Common Incubation Problems: Causes and Remedies. Publication 8127, 2004.

Available for free downloading from the ANR Communication Services Web site, http://anrcatalog.ucdavis.edu/pdf/8127/pdf.

Visit the ANR Communication Services online catalog at http://anrcatalog.ucdavis.edu. You can also place orders by mail, phone, or FAX, or request a printed catalog of our products from:

University of California

Agriculture and Natural Resources

Communication Services

6701 San Pablo Avenue, 2nd Floor

Oakland, California 94608-1239

Telephone: (800) 994-8849 or (510) 642-2431; FAX: (510) 643-5470

E-mail inquiries: danrcs@ucdavis.edu

An electronic version of this publication is available on the ANR Communication Services Web site at http://anrcatalog.ucdavis.edu.

\section{Publication 8134}

(C) 2004 by the Regents of the University of California, Division of Agriculture and Natural Resources. All rights reserved.

The University of California prohibits discrimination or harassment of any person on the basis of race, color, national origin, religion, sex, gender identity, pregnancy (including childbirth, and medical conditions related to pregnancy or childbirth), physical or mental disability, medical condition (cancer-related or genetic characteristics), ancestry, marital status, age, sexual orientation, citizenship, or status as a covered veteran (covered veterans are special disabled veterans, recently separated veterans, Vietnam era veterans, or any other veterans who served on active duty during a war or in a campaign or expedition for which a campaign badge has been authorized) in any of its programs or activities.

University policy is intended to be consistent with the provisions of applicable State and Federal laws.

Inquiries regarding the University's nondiscrimination policies may be directed to the Affirmative Action/Staff Personnel Services Director, University of California, Agriculture and Natural Resources, 300 Lakeside Drive, 6th Floor, Oakland, CA 94612-3550, (510) 987-0096. For a free catalog of other publications, call (800) 994-8849. For help downloading this publication, call (530) 754-5112.

pr-5/04-SB/CR

ISBN 978-1-60107-313-6

This publication has been anonymously peer reviewed for technical accuracy by University of California scientists and other qualified professionals. This review process was managed by the ANR Associate Editor for Animal, Avian, Aquaculture, and Veterinary Sciences. 